\title{
Inhibitory Effect of Neem Leaves on Glucose Transport
}

\author{
Lia Safitrie Johansyah, ${ }^{1}$ Vycke Yunivita, ${ }^{2}$ Anna Martiana, ${ }^{2}$ Augusta Y. L. Arifin ${ }^{3}$ \\ ${ }^{1}$ Faculty of Medicine Universitas Padjadjaran, Indonesia, ${ }^{2}$ Department of Biomedical Sciences \\ Faculty of Medicine Universitas Padjadjaran, Indonesia ${ }^{3}$ Department of Internal Medicine Faculty \\ of Medicine Universitas Padjadjaran/Dr. Hasan Sadikin General Hospital Bandung, Indonesia
}

\section{Abstract}

Background: Neem leaf is known as a diabetic herbal treatment in India, however, its antihyperglycemic effect and the mechanism is still unknown. Quercetin is proven to inhibit glucose transporter in the small intestine, and this active substance is present in Neem leaves. The study was conducted to explore the inhibitory effect of Neem leaves infusion on glucose transport and whether the effect was reversible or irreversible.

Methods: This study was conducted in the Biochemistry Laboratory Faculty of Medicine Universitas Padjadjaran in the period of October to November 2012 by using in situ perfusion method. Five male Wistar rats were given three treatments; glucose as initial control, glucose with Neem infusion, and glucose again as last control. The samples of perfusion solution were taken for every treatment and were measured using spectrophotometry method.

Results: There was a reduction in glucose absorption $(15.9 \%)$ between the first $(47.28+17.57 \mathrm{mg} / \mathrm{dL})$ and the second treatment $(39.75+14.85 \mathrm{mg} / \mathrm{dL})$. The transported glucose level in the third treatment was further reduced after the first treatment $(37.15+13.15 \mathrm{mg} / \mathrm{dL})$.

Conclusions: Neem leaves infusion has inhibitory effect on glucose transport that irreversibly reduced further. Further study is needed with a larger sample size to confirm this phenomenon.

Keywords: Antihyperglycemic, glucose transporte, Neem leaves

\section{Introduction}

Diabetes Mellitus is a disease with high morbidity and mortality rates in the world, not only in developed countries but also in developing countries, including Indonesia. ${ }^{1,2}$ Diabetes Mellitus is a metabolic disease in which the patients have impaired insulin secretion, insulin action, or both that cause hyperglycemia and result in organ damage and organ failure. ${ }^{3}$ The goal of therapy in this disease is to restore blood glucose level to normal, as in a medical practice, there are four types of therapy given to patients with diabetes mellitus, lifestyle education, eating habits, physical exercise, and pharmacology, 3,4

Herbal treatment is one of the traditional medicines that uses different parts of the plant from the roots, stems and leaves..$^{5}$ Neem is one of diabetic herbal medicines and is popularly used, especially in India. Many studies have been conducted to prove antihyperglycemic effect of Neem, especially of the leaves. ${ }^{6-11}$ However, the mechanism of Neem leaves in lowering blood glucose level is still unknown..$^{10}$ Quercetin is a flavonoid compound. According to research conducted by Cermak et al. $^{12}$, quercetin isolates were proven to inhibit SGLT1 (sodium-dependent glucose transporter 1) in the small intestine. Quercetin is found in many plants including in Neem leaves, so it is possible that the antihyperglycemic effect of Neem leaves is through the inhibition of glucose transporter. ${ }^{13}$ The study was conducted to verify the inhibitory effect of Neem leaves infusion on glucose transporter and whether the effect was reversible or irreversible.

\section{Methods}

This was an exploratory study, using five male Wistar rats aged 3-4 months, weighing 150250 grams. ${ }^{14}$ The study was approved by the Health Research Ethics Committee of Faculty of Medicine Universitas Padjadjaran and was conducted in Biochemistry Laboratory of Faculty of Medicine Universitas Padjadjaran started in October to November 2012. 
This study used an in situ perfusion method. The tools were from the Department of Physics, Institut Teknologi Bandung and it was designed by P. Soedigdo and Marsongkohadi. This tools flowed perfusion solution 6 times per minute and made the rat small intestine to function normally for 6-8 hours. ${ }^{14}$

Neem leaves infusion was made by mixing $200 \mathrm{~g}$ Neem leaves (Azadirachta indica A. Juss $L$ ) with $200 \mathrm{~mL}$ of aquadest and heated at $90^{\circ} \mathrm{C}$ for 15 minutes. All rats were adapted for 7 days with food and drink and prior to the research, the rat was fasted for 18-24 hours. The rat was anesthetized with ketamine and rat limbs were fixed on board as a preparation at the laboratory of the Department of Biochemistry Faculty of Medicine, Universitas Padjadjaran. Rat abdominal was cleaned with alcohol and dissected until the small intestine became visible. Rat small intestine was mounted with two cannulas, the first cannula was placed $10 \mathrm{~cm}$ from the pylorus to the distal and the second was placed $25 \mathrm{~cm}$ from the first to the proximal. The small intestine was cleaned with a solution of $\mathrm{NaCl}$ and blown three times. Then cannulas were connected to the vessels of perfusion tools through rubber tubes. Vessels were filled with a solution of the experiment and the sample was taken every 15 minutes. ${ }^{14}$

This study was an explorative study of the effect of infusion of Neem leaves, no sample size calculation was performed. It used five male Wistar rats and each rat was given three treatments. In the first treatment, rat small intestine was flowed with glucose, whereas in the second one, rat small intestine was given glucose with Neem leaves infusion. The last treatment was similar to the first one. In every treatment, rat small intestine was always cleaned with a solution of $\mathrm{NaCl}$ and blown three times. ${ }^{14}$
The samples of perfusion solution in every treatment were given Peridochrom Glucose/ GOD-PAP reagent kit. Then the samples were read using spectrophotometry with a wavelength of $505 \mathrm{~nm} .{ }^{14,15}$

The glucose level of the samples was calculated using the formula. ${ }^{15}$ The glucose levels were shown into tables. One sample t-test was conducted to analyze the data. All of the data were processed by SPSS (Statistics Package for Social Science) version 15. ${ }^{16}$

\section{Results}

Data analysis between the first and the second treatment aimed to determine the effect of Neem leaves infusion on glucose transporter. Data analysis between the first and the third treatment aimed to determine the nature of the barriers of Neem leaves infusion. The transported glucose level in all treatments was presented in Table 1.

There was a reduction in glucose absorption $(15.9 \%)$ between the first $(47.28+17.57 \mathrm{mg} /$ $\mathrm{dL})$ and the second treatment $(39.75+14.85$ $\mathrm{mg} / \mathrm{dL}$ ). The transported glucose level in the third treatment was further reduced after the first treatment $(37.15+13.15 \mathrm{mg} / \mathrm{dL})$ (Table 1).

The comparison of glucose level between first and second treatment was presented in Figure 1. The comparison of glucose level between first and third treatment was presented in Figure 2.

From Table 1 and Figure 2 it was found the difference in transported glucose level between the first and the third treatment, in which transported glucose level in the third treatment was lower than the first one.

Table 1 Transported Glucose Level in First, Second and Third Treatment

\begin{tabular}{cccc}
\hline Rats no. & $\begin{array}{c}\text { Glucose level pre- } \\
\text { treatment } \\
\text { (mg/dL) }\end{array}$ & $\begin{array}{c}\text { Glucose level with } \\
\text { Neem leaves infusion } \\
\text { (mg/dL) }\end{array}$ & $\begin{array}{c}\text { Glucose level after } \\
\text { treatment } \\
\text { (mg/dL) }\end{array}$ \\
\hline 1 & 78.21 & 66.27 & 58.51 \\
2 & 37.26 & 33.03 & 34.80 \\
3 & 44.33 & 34.38 & 37.94 \\
4 & 40.34 & 32.48 & 31.32 \\
5 & 36.25 & 32.58 & 23.17 \\
Mean + sd. & $47.28+17,57$ & $39.75+14,85$ & $37.15+13,15$ \\
\hline
\end{tabular}

Note: SD=Standard Deviation 


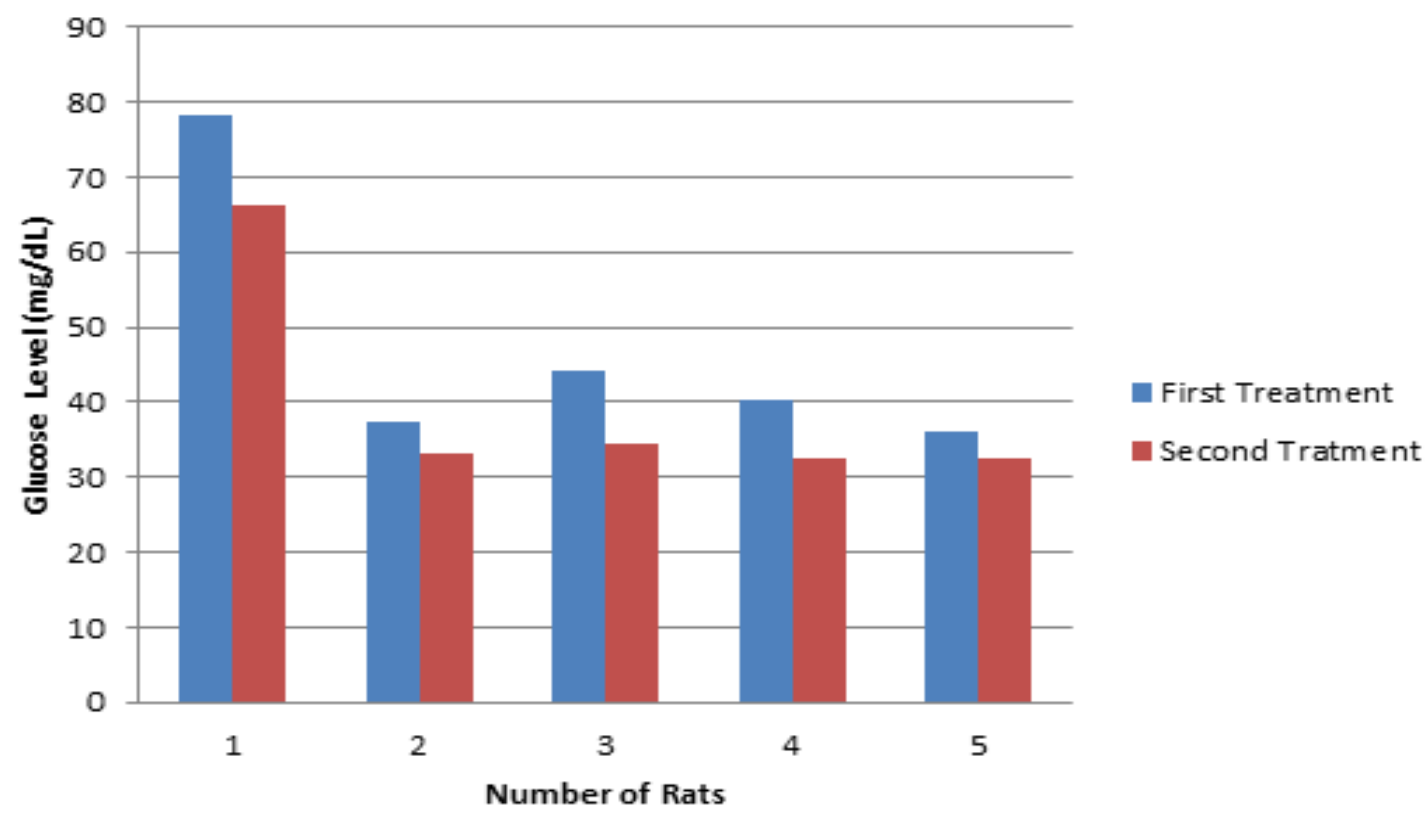

Figure 1 Mean of Total Blood Cholesterol Level

\section{Discussion}

Hypothesis testing in this study with a 95\% confidence interval concluded that Neem leaves infusion had an effect on glucose level. In this study, the result of statistical analysis was significant $(p<0.05)$ between the first and the second treatment. From Figure 1, it was found the difference in transported glucose level between the first and the second treatment in which the graph showed a reduction in glucose absorption while using Neem leaves infusion. FromTtable 1, it was calculated the percentage of inhibited glucose level by $15.9 \%$. This result was similar with an earlier study by Cermak et al. ${ }^{12}$, that suggested an interaction

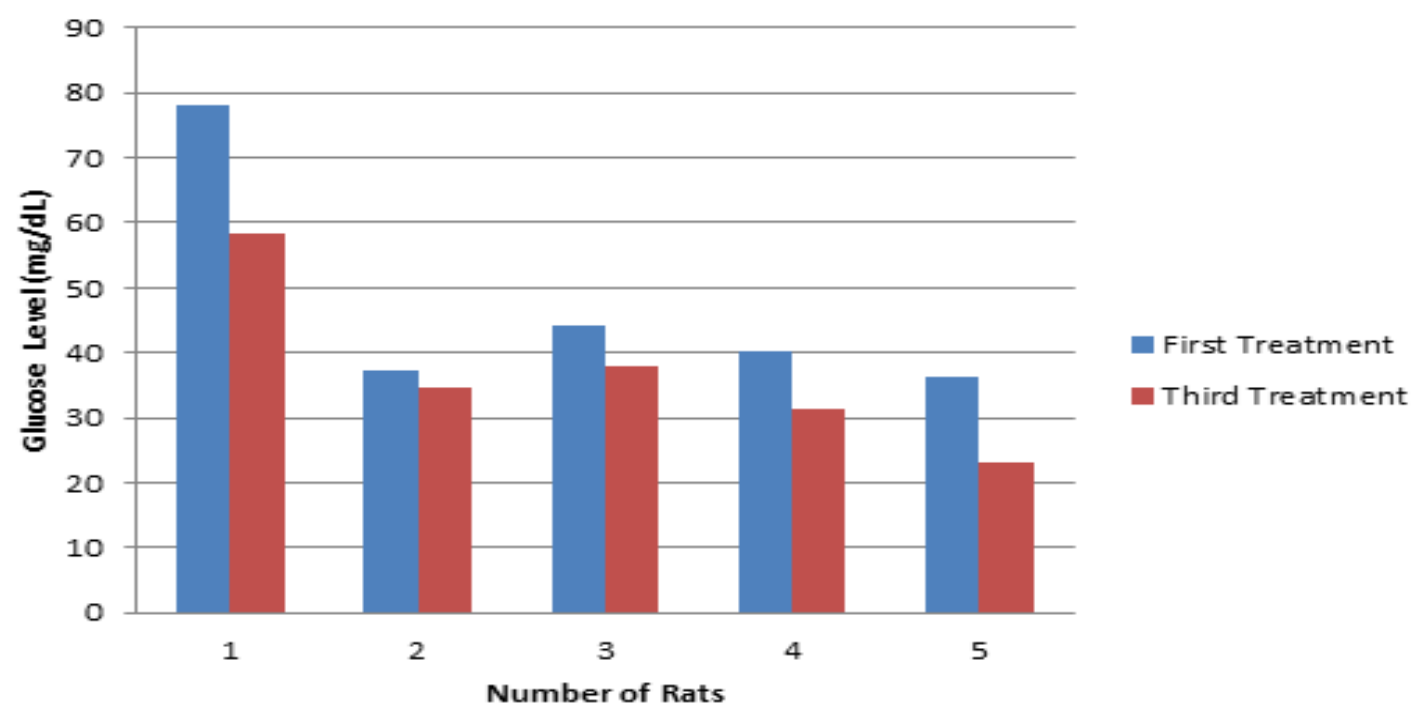

Figure 2 Comparison of Transported Glucose Level in First and Third Treatment 
of quercetin with SGLT1. Quercetin was one of the active substance in Neem leaves and it acts as a competitive inhibitor of SGLT1 that reduced glucose absorption and generated antihyperglycemic effect. ${ }^{12,13}$

The inhibitory effect of Neem leaves infusion was irreversible. The result of statistical analysis in this study was significant $(p<0.05)$ between the first and the third treatment. From Table 1 and Figure 2 it was found the difference in transported glucose level between the first and the third treatment, in which transported glucose level in the third treatment was lower than the first one. It indicated that after administration of Neem leaves infusion, levels of glucose absorption did not return to normal in the first one hour of the treatment.

In conclusion, Neem leaves infusion has an inhibitory effect on glucose transporter irreversibly for one hour after the treatment. The results of this study can be socialized to the public, especially people who use herbal treatment of diabetes. Study with larger sample size or other study related to dose and toxicity of Neem leaves infusion need to be conducted to examine further the role of the leaves in diabetes treatment.

\section{References}

1. WHO. 10 Facts about Diabetes. Geneva; 2012 [downloaded in 15 April 2012]; Available at: http://www.who.int/ features/factfiles/diabetes/facts/en/ index.html.

2. Kementerian Kesehatan Republik Indonesia. Tahun 2030 Prevalensi Diabetes Melitus Di Indonesia Mencapai 21,3 Juta Orang. Jakarta; 2009 [downloaded in 9 April 2012]; Available at: http://www. depkes.go.id/index.php/berita/pressrelease/414-tahun-2030-prevalensidiabetes-melitus-di-indonesia-mencapai213-juta-orang.html.

3. WHO. About Diabetes. Geneva; 2012 [downloaded in 9 April 2012]; Available at: http://www.who.int/diabetes/action online/basics/en/index.html.

4. Perkumpulan Endokrinologi Indonesia. Konsensus Pengelolaan dan Pencegahan Diabetes Mellitus Tipe 2 di Indonesia. Jakarta: PB PERKENI; 2006.

5. WHO. Trips, CBD and Traditional Medicines: Concepts and Questions. Geneva; 2012 [downloaded in 16 April
2012]; Available at: http://apps.who.int/ medicinedocs/en/d/Jh2996e/\#Jh2996e.

6. Akinola OB, Dosumu OO, Akinola OS, Zatta L, Dini L, Caxton-Martins EA. Azadirachta indica Leaf Extract Ameliorates Hyperglycemia and Hepatic Glycogenosis in Streptozotocin-induced Diabetic Wistar Rats. IJOP. 2010;2:320-31.

7. Mostofa M, Choudhury ME, Hossain MA, Islam MZ, Islam MS, Sumon MH. Antidiabetic Effects of Catharanthus roseus, Azadirachta indica, Allium sativum and Glimepride in Experimentally Diabetic Induced Rat. Bangl J Vet Med. 2007;5(1 \& 2):99-102.

8. Dutta M, Raychaudhuri U, Chakroborty R, Maji D. Role of Diet and Plants on Diabetic Patients - a Critical Appraisal. Science and Culture. 2011;77:115-22.

9. AyodhyaS, KusumS,AnjaliS. Hypoglycaemic Activity of Different Extracts of Various Herbal Plants. IJRAP. 2010;1(1):212-24.

10. Maithani A, Parcha V, Pant G, Dhulia I, Kumar D. Studies on Phytochemical Investigation And Hypoglycemic Evaluation of Azadirachta Indica Leaves Extract on Alloxan Induced Diabetic Rats. JPR. 2011;4(3):759-60.

11. Das AR, Mostofa M, Hoque ME, Das $S$, Sarkar AK. Comparative Efficacy of Neem (Azadirachta indica) and Metformin Hydrochloride (Comet $囚$ ) in Streptozotocin Induced Diabetes Melitus in Rats. Bangl J Vet Med. 2010;8(1):75-80.

12. Cermak R, Landgraf $S$, Wolffram $S$. Quercetin glucosides inhibit glucose uptake into brush-border membrane vesicles of porcine jejunum. Br J Nutr. 2004;91:849-55.

13. Shah W, Rane N, Kekare M.B, Vaidya V. Estimation of Two Bioactive Compounds from Azadirachta indica A.Juss. Leaves Using HPLC. IJPBS. 2010;1(2):1-7.

14. Rohmawaty E, Yunivita V, Potensi Quercetin-30-Glucoside (Q3G) dan Quercetin-4-0-Glucoside (Q4G) dari Daun Mimba(Azadirachtaindicaa.juss) terhadap Ambilan Glukosa. MKB. 2016:48(4):222-7.

15. Fortress Diagnostic. Glucose GODPAP. London; 2012 [downloaded in 12 December 2012]; Available at: http:// www.fortressdiagnostics.com/online/.

16. Dahlan MS. Statistik untuk Kedokteran dan Kesehatan. 5th ed. Jakarta: Salemba Medika; 2011. 